\title{
FILOSOFIA DA CULTURA E EDUCAÇÃO: AS IMPLICAÇÕES SIMBÓLICAS E CULTURAIS REGIONAIS/LOCAIS NA PRÁTICA PEDAGÓGICA ESCOLAR NO CONTEXTO DE UMA ESCOLA EM FEIRA DE SANTANA/BA.
}

\author{
André Conceição Costa ${ }^{1}$; Miguel Almir de Araújo ${ }^{2}$ \\ 1. Bolsista PIBIC/CNPq, Graduando em Filosofia e mestrando em Desenho, Cultura e Interatividade, Universidade \\ Estadual de Feira de Santana, e-mail: andrecostapsique@gmail.com \\ 2. Orientador, Departamento de Educação, Universidade Estadual de Feira de Santana, e-mail: malmir2@gmail.com
}

PALAVRAS-CHAVE: filosofia; cultura; educação.

\section{INTRODUÇÃO}

A Filosofia é um campo do conhecimento humano preliminar para outros tipos de conhecimentos. A cultura é um aglomerado de sentidos, símbolos e práticas que se evidenciam nas pessoas e nos povos, nas individualidades e nas coletividades. A cultura e a filosofia são imprescindíveis ao próprio existir humano. $O$ ser humano existe culturalmente em sua coexistência com o outro.

As investigações filosóficas sobre a cultura estabelecem reflexões que contribuem para um entendimento mais aprofundado desse aglomerado de sentidos humanos. A filosofia em diálogo com a cultura, estabelece, em sua compreensão, a delimitação do conceito de cultura constituindo um modo específico de pensar a cultura. A cultura enquanto ação humana é a capacidade simbólica do ser humano que o permite atribuir sentidos a sua existência. É tudo aquilo que ele elabora através de sua subjetividade e traz significação aos fenômenos e a sua existência. Por fim, nas inferências advindas dessa experiência de criar e recriar a sua própria existência, este mesmo ser humanose vê mergulhado numa coexistência de sentidos e símbolos.

A escola é, sem dúvida, uma instituição cultural. Deste modo, as correlações entre escola e cultura não podem ser entendidas como dois campos independentes do fazer humano, mas sim como campos fenomênicos entrecruzados. Assim, partindo dessas afirmações e acentuando a íntima associação entre educação e cultura, filosofia e cultura, ao observar suas relações como intrinsecamente constitutivas do campo fenomênico educacional, cabe questionar por que hoje essa compreensão ainda se apresenta como uma prática e reflexão desafiadora para as ações educativas. A escola, enquanto instituição cultural e lugar da intersubjetividade precisa ser o lugar em que a pluralidade de culturas e os saberes culturais possam encontrar espaços fecundos. A problemática das relações entre educação e cultura, cultura e filosofia é intrínseco a todo fazer educativo no contexto escolar. Toda forma de educação está inserida,na cultura da humanidade.

Partindo destes pressupostos, a questão que orienta esta pesquisa está em identificar as implicações simbólicas e culturais regionais/locais na prática pedagógica escolar. Deste modo o objetivo deste trabalho é investigar a relevância, bem como, a presença (ou ausência) dos saberes culturais que revelam os sentidos e os valores da vida dos sujeitos em suas comunidades, no cotidiano da prática escolar, identificando o modo como essa experiência acontece no contexto de duas escolas em Feira de Santana e como estas expressões culturais contribuem na formação do pensamento crítico, dos 
valores humanos. Para a elaboração desta pesquisa entrevistamos 10 estudantes e 5 professores para construção dos dados da pesquisa.

\section{MATERIAL E MÉTODOS OU METODOLOGIA (ou equivalente)}

A metodologia da investigação/pesquisa foirealizada tendo como referencial as metodologias qualitativas de pesquisaque orientam-senos fundamentos da Fenomenologia e da abordagem Hermenêutica.

A pesquisa/investigação fundamenta-se na abordagem fenomenológica na medida em que as investigações se baseiam nas manifestações cotidianas dos fenômenos culturais.Nesse sentido, a subjetividade e a objetividade são consideradas como campos fenomênicos indissociáveis, em que os pesquisadores participam ativamente do processo de conhecimento e interpretam os fenômenos traduzindo seus significados.

Desta forma, foram elaboradas atividades de campo com a finalidade de articular e estabelecer contatos diretos com os/as protagonistas dos repertórios da temática pesquisada. Chizzotti (1998, p. 79) afirma que "o sujeito observador é parte integrante do processo de conhecimento e interpreta os fenômenos atribuindo-lhes significados".

As pesquisas qualitativas baseiam-se na Hermenêutica na medida em que esta ressalta a interpretação dos significados e sentidos que podem ser compreendidos através dos fenômenos. Deste modo, a compreensão acontece dentro do contexto histórico-cultural em que os fenômenos acontecem enquanto expressões culturais. Os indivíduos, em suas subjetividades, são os principais agentes de ação na produção de significados e sentidos. Deste modo, a compreensão se faz mediante o dinamismo dos processos de interpretação que ocorrem de maneira flexível e dialógica.

Nesse campodas pesquisas qualitativas salientamos o contexto escolar e sua relação com os saberes culturais no sentido em que procurarei compor descrições e interpretações críticas e contextuais a partir do contato direto com os sujeitos na ação de pesquisar. Chizzotti (1998, p. 79), afirma: “A abordagem qualitativa parte do fundamento de que há uma relação dinâmica entre o mundo real e o sujeito, uma interdependência viva entre o sujeito e o objeto, um vínculo indissociável entre o mundo objetivo e a subjetividade do sujeito". Neste sentido, o método de compreensão dos fenômenos se dá em relação com o universo de valores e sentires, de crenças e práticas cotidianas que caracterizam as subjetividades, incluindo, neste contexto, o próprio investigador.

No processo investigativo, a partir do projeto "Coexistência entre Cultura/s e Educação: a relevância dos repertórios simbólicos da/s Cultura/s, da diversidade cultural no cotidiano da educação escolar", utilizamos os seguintes procedimentos: entrevistas abertas, questionários, observação participante, além de uma investigação bibliográfica sobre o tema pesquisado.

\section{RESULTADOS E/OU DISCUSSÃO (ou Análise e discussão dos resultados)}

A pesquisa percorreu alguns momentos para a sua elaboração, inicialmente entramos em contato com a instituição escolar colégio Estadual Prof ${ }^{a}$ Maria José de Lima Silveira, para marcamos uma primeira visita e apresentar a pesquisa aos gestores e 
professores, ocolégio Estadual Prof ${ }^{a}$ Maria José de Lima Silveira situa-se no distrito de São José, escola de educação básica: ensino fundamental II e Médio). Neste momento inicial percebemos a receptividade da equipe escolar, apresentamos os variados aspectos da pesquisa e respondemos as dúvidas de alguns professores sobre a operacionalidade da pesquisa.

Entrevistamos alguns professores e gestores, o número estabelecido sob o critério de obtermos informações substanciadas e com o intuito de comparar e analisar os resultados construídos para fins já estabelecidos pelo Plano de Trabalho, a saber: investigar a relevância, bem como, as implicações dos saberes culturais que revelam os sentidos e os valores da vida dos sujeitos em suas comunidades, nas práticas pedagógicas escolares, identificando o modo como essas implicações se revelam no contexto de uma escola em Feira de Santana e como esta contribui na formação do pensamento crítico, dos valores humanos.

Os resultados alcançados da pesquisa foram obtidos por meio do material proposto no plano de trabalho e pelo projeto de pesquisa, a saber: as entrevistas abertas, questionários, fotografias e filmagens. Este material submetido à análise, evidenciou variados aspectos do fenômeno do qual nos propusermos investigar.

Observamos que o Colégio Estadual Prof ${ }^{a}$ Maria José de Lima Silveira, promove atividades culturais que têm como temas centrais a consciência negra e culturas regionais. A partir destes dados analisamos que a escola é, sem dúvida, o lugar de partilhamento cultural. Deste modo, as correlações entre as práticas pedagógicas e culturais não podem ser entendidas como dois campos independentes, mas sim como campos fenomênicos entrecruzados. Assim, partindo dessas afirmações e acentuando a íntima associação entre educação, cultura e filosofia, ao observar suas relações como intrinsecamente constitutiva do campo educacional cabe questionar como essas implicações se apresentam como uma prática e reflexão desafiadora para as ações pedagógicas. A escola, enquanto instituição cultural e lugar da intersubjetividade, precisa ser o lugar em que a pluralidade de culturas e os saberes culturais possam encontrar espaços fecundos.

\section{CONSIDERAÇÕES FINAIS (ou Conclusão)}

As investigações realizadas no Colégio Estadual Prof ${ }^{a}$ Maria José de Lima Silveira, levaram-nos a concluir que as implicações e os saberes das culturas regionais/locais, que traduzem as crenças, os valores, os sentidos da vida dos sujeitos que fazem parte da escola, de certo modo, ainda são considerados e ressignificado a um tipo de discurso apropriado ao contexto escolar e pedagógico nesta escola especificamente.

A relação entre cultura e educação neste contexto, está na intercessão do fazer pedagógico e instituição de ensino. O lugar da escola enquanto um lugar geográfico significativo para a formação da pessoa humana em seus aspectos éticos, culturais e intelectuais não se constitui sem a presença dos símbolos culturais da comunidade em que está inserida. Assim, pode-se compreender que o fazer pedagógico também se traduz na redescoberta dos valores locais, costumes e cotidiano da comunidade entorno da escola.

A filosofia se faz presente na reflexão destes valores, o modo de conceber a cultura e sua relação com a vida comunitária é o que traduz a relação entre filosofia e cultura. Pensar a cultura se fundamenta na medida em que cada participante da escola e 
da comunidade em seu entorno fala sobre a importância destes saberes, e faz relações com outros diversos saberes: ciências, artes, linguagens, senso comum.

Esta pesquisa não fecha a discussão que se tem sobre a relação entre cultura, educação e filosofia, mas dá continuidade à reflexão que se pode fazer sobre o sentido destes saberes e práticas educacionais e culturais.

\section{REFERÊNCIAS}

ARAÚJO, Miguel Almir L. de. Laços de encruzilhada: ensaios transdisciplinares. Feira de Santana: UEFS, 2001.

ARAÚJO, Miguel Almir L. de. Os Sentidos da Sensibilidade: sua fruição no fenômeno doeducar. Salvador: EDUFBA, 2008.

CASCUDO, Luis da Câmara. Dicionário do folclore brasileiro. Brasília: INL/MEC, 1972.

CASSIRER, Ernst. Ensaio sobre o homem: introdução a uma filosofia da cultura humana.

São Paulo: Martins Fontes, 1997.

CHIZZOTTI, Antonio. Pesquisa em ciências humanas e sociais. São Paulo: Cortez, 1998.

COSTA, Marisa Verraber (Org.). Caminhos investigativos: novos olhares na pesquisa em

Educação. Porto Alegre: Mediação, 1996.

FORQUIN, Jean-Claude. Escola e cultura: as bases sociais e epistemológicas do conhecimento escolar. Porto Alegre: Artes Médicas, 1993

FREIRE, Paulo. Pedagogia da autonomia: saberes necessários à prática educativa. Rio deJaneiro: Paz e Terra, 1996.

Rio

. Pedagogia da esperança: um reencontro com a Pedagogia do oprimido.

de Janeiro: Paz e Terra, 1992.

. Ação cultural para a liberdade. Rio de Janeiro: Paz e Terra, 1981.

FREIRE, Paulo. Pedagogia da autonomia: saberes necessários à prática educativa. Rio de

Janeiro: Paz e Terra, 1996.

Pedagogia da esperança: um reencontro com a Pedagogia do oprimido.

Rio

de Janeiro: Paz e Terra, 1992.

. Ação cultural para a liberdade. Rio de Janeiro: Paz e Terra, 1981.

GADAMER, Hans Georg. Verdade e método: traços fundamentais de uma hermenêutica

filosófica. Petrópolis, RJ: Vozes, 1997.

LUDKE, Menga e ANDRÉ, Marli E. D. A. Pesquisa em educação: abordagens

qualitativas.São Paulo: EPU, 1986.

MORAIS, Regis de. Estudos de Filosofia da Cultura. São Paulo: Loyola, 1992.

MORIN, Edgar. Sete saberes necessários à educação do futuro. São Paulo: Cortez;

Brasília, DF: UNESCO, 2000. 